\title{
Dynamic Mechanical Properties and Damage Mechanism of Freeze-Thaw Sandstone under Acid Corrosion
}

\author{
Xiaoxiao Cao $\mathbb{D},{ }^{1,2}$ Meimei Feng $\mathbb{D},{ }^{1,2}$ and Kangsheng Yuan ${ }^{1,2}$ \\ ${ }^{1}$ State Key Laboratory for Geomechanics \& Deep Underground Engineering, China University of Mining \& Technology, Xuzhou, \\ Jiangsu 221116, China \\ ${ }^{2}$ School of Mechanics \& Civil Engineering, China University of Mining \& Technology, Xuzhou, Jiangsu 221116, China
}

Correspondence should be addressed to Meimei Feng; fengmeimei@cumt.edu.cn

Received 8 September 2021; Revised 9 October 2021; Accepted 12 November 2021; Published 8 December 2021

Academic Editor: Afshin Davarpanah

Copyright (c) 2021 Xiaoxiao Cao et al. This is an open access article distributed under the Creative Commons Attribution License, which permits unrestricted use, distribution, and reproduction in any medium, provided the original work is properly cited.

During the construction of geotechnical engineering in cold regions, the stability of rock is inevitably affected by freeze-thaw cycles and hydrochemical corrosion. In order to study the effect of hydrochemical corrosion on dynamic mechanical properties of freeze-thaw rocks, dynamic compression tests were carried out on sandstone samples corroded by four different concentrations of $\mathrm{HCl}$ solutions with the same number of freeze-thaw cycles using split-Hopkinson pressure bar (SHPB) test system. The coupling effects of freeze-thaw cycles with different concentrations of $\mathrm{HCl}$ solutions and strain rate on mechanical properties of sandstones were explored. The results showed that strain rate could enhance the dynamic compressive strength and peak strain but had no significant effect on the elastic modulus. The coupling effect of freeze-thaw cycles and acid corrosion weakened the dynamic compressive strength, and elastic modulus but enhanced the peak strain. In addition, X-ray diffractometer (XRD) and scanning electron microscope (SEM) were used to analyze the changes of mineral composition and microstructure damage of sandstone samples under the coupling effect of acid corrosion and freeze-thaw cycles. The analysis results were basically consistent with the damage characteristics of macro mechanical properties. The research results can provide reference for open pit coal mining in cold regions.

\section{Introduction}

China has abundance of coal resources, but they are not evenly distributed. More than $95 \%$ of open-pit coal mines are located in cold regions north of $38^{\circ} \mathrm{N}$ latitude. To increase the efficiency of coal mining via safety and stability, many scholars have conducted extensive study in areas such as roadway excavation $[1,2]$, stability monitoring $[3,4]$, and resource utilization [5]. However, due to seasonal variations and the diurnal cycle, freeze-thaw damage is unavoidable in coal mining. There have been episodes of low temperatures below $0^{\circ} \mathrm{C}$ in the past 8 months at the Xinjiang Beitashan Pasture Open-Pit Coal Mine [6]. In open-pit coal mines, bench blasting is the primary method of production. The intensity of blasting steadily increases in high-intensity mining conditions. According to real measurements, the stress wave produced by blasting may cause strain rates in the range of $10^{1}-10^{3} \mathrm{~s}^{-1}$ in the rock mass [7], which corresponds to normal high impact dynamic loading. Several investigations reveal that the mechanical response characteristics and failure law of rock mass under dynamic stress differ considerably from those under static load $[8,9]$. As a result, it is critical to investigate the dynamic impact test of rock under freeze-thaw cycles for coal mining in cold regions.

Rock materials are cemented by various mineral particles, and there are holes and fissures in the process of diagenesis. Under the influence of freeze-thaw cycles, the frost heaving force caused by the transformation of fracture water into ice is the main damage mechanism of rock freeze-thaw cycles $[10,11]$. The factors affecting rock freeze-thaw strength mainly include rock type, temperature, water content, and freeze-thaw cycle times $[12,13]$. Scholars at home and abroad have done a lot of research on changes of static mechanical properties of rock under freeze-thaw cycles [14, 15]. With the development of coal mining in cold regions, some scholars have paid attention to dynamic mechanical 
properties of rock under freeze-thaw cycles. Li et al. [16] carried out a dynamic impact test on sandstone after freezethaw cycle, analyzed the change of pore structure after freeze-thaw cycle by combining with nuclear magnetic resonance technology, and explained the reason of degradation of dynamic strength. Based on the energy change during the dynamic failure process of red sandstone, Wang et al. [17] proposed an analysis method of damage evolution process after freeze-thaw cycles. Zhou et al. [18] carried out nuclear magnetic resonance (NMR) and dynamic compression tests on the frozen and thawed sandstone. The results showed that the dynamic elastic modulus and peak strength of sandstone decreased with the increase of freeze-thaw cycles, and the relationship between porosity and dynamic peak strength was polynomial. Ma et al. [19] carried out dynamic compression tests on sandy mudstone and mudstone with different freeze-thaw cycles. The results showed that the compressive strength decreased logarithmically with the increase of freeze-thaw cycles. Lu et al. [20] verified the influence trend of damage effect on the compressive strength of concrete by observing the microcrack growth trend. At present, the research achievements in this field mainly focus on dynamic compression mechanical properties of rock under freeze-thaw cycles. However, the actual underground environment is often intricate, and water-rock interaction has become a problem that cannot be ignored in geological engineering. Existing scholars have done related research on water-rock interaction, for example, Liu et al. [21, 22] and $\mathrm{Yu}$ et al. [23] have done related research on the permeability of rock fissures. But obviously these studies are far from enough. Groundwater, as the main factor affecting freeze-thaw cycle, contains different ionic components and $\mathrm{pH}$. It is a complex hydrochemical solution. Under the action of freeze-thaw cycle, ground water produces frost heaving force and corrodes rocks in varying degrees. Therefore, not only freeze-thaw cycles but also water-rock interaction should be considered in rock mass engineering in cold regions.

In recent years, the mechanical properties of rock under freeze-thaw cycles and water-rock interaction have been concerned by scholars all over the world. Han et al. [24] analyzed the variation of mechanical properties of sandstone under different chemical solutions and freeze-thaw cycles. They concluded that strong alkaline solution can inhibit the freeze-thaw damage of sandstone when the freeze-thaw cycles were less than 25. Han et al. [25] quantitatively analyzed the damage degree of mechanical properties of sandstone under freeze-thaw cycles and different chemical solutions. Yang et al. [26] studied the damage effect of the mechanical properties of quartz sandstone, quartzite, and four different chemical solutions under the action of freeze-thaw cycles and verified it by analyzing the microstructure damage mechanism with scanning electron microscope (SEM). Gao et al. [27] studied the influence of the chemical environment and freeze-thaw cycle coupling on the damage characteristics of red sandstone. Qu et al. [28] and $\mathrm{Li}$ et al. [29] established damage evolution models, respectively, for the mechanical properties of sandstone under chemical corrosion and freeze-thaw cycles. Zhang et al. [30] studied the degradation of mechanical properties of sandstone under rapid freeze-thaw cycles and chemical corrosion and further studied the variation of rock splitting tensile strength and point load index with freeze-thaw cycles by using the attenuation function model. However, the current research results mainly focus on the study of static mechanical properties of rocks under freeze-thaw cycles and water-rock interactions. There are few studies on dynamic mechanical properties of rocks under freeze-thaw cycles and water-rock interaction. Under such background, this paper will study dynamic mechanical properties of rocks under freeze-thaw cycles and water-rock interaction, hoping to provide references for further related research.

In this paper, $\mathrm{HCl}$ solution will be used to simulate the hydrochemical environment of rock samples. Dynamic compression tests will be carried out on sandstone samples with different concentrations of $\mathrm{HCl}$ solutions under freeze-thaw cycles. The influence of varying concentrations of $\mathrm{HCl}$ solutions and freeze-thaw cycles on the strength and deformation properties of sandstone samples will be discussed, as well as the effect of strain rate. In order to accurately analyze the micromechanism change of samples, $\mathrm{X}$ ray diffractometer (XRD) and scanning electron microscopy (SEM) will be used to analyze the mineral composition, variation, and internal damage of samples.

\section{Materials and Methods}

2.1. Preparation of Test Materials and Samples. The sandstone samples selected in this test were taken from a coal mine slope in Xinjiang, China. The main components are quartz, kaolinite, and muscovite. The longitudinal wave velocity of the sample is $1.7 \mathrm{~km} / \mathrm{s}$, the density is $2.14 \mathrm{~g} / \mathrm{m}^{3}$, and the static compressive strength is $14.7 \mathrm{MPa}$. According to the requirements of rock mechanics testing regulations, rock samples were cut into $\Phi 50 \times 25 \mathrm{~mm}$ cylindrical standard specimens. After that, specimens were ground to ensure that the parallelism of the end face was less than $0.05 \mathrm{~mm}$ and the flatness was less than $0.02 \mathrm{~mm}$ [31].

In order to study the effect of acid corrosion of groundwater on mechanical properties of sandstones in cold regions, four concentrations of $\mathrm{HCl}$ solutions $(0 \mathrm{~mol} / \mathrm{L}$, $0.01 \mathrm{~mol} / \mathrm{L}, 0.1 \mathrm{~mol} / \mathrm{L}$, and $1 \mathrm{~mol} / \mathrm{L})$ were selected. After the solution preparation was completed, we used a highprecision $\mathrm{pH}$ detection pen to measure the $\mathrm{pH}$ value of the solution. The corresponding $\mathrm{pH}$ values were $7.0,5.8,3.2$, and 1.1 , respectively. Considering the time effect of initial compressive strength and chemical corrosion, 10 freezethaw cycles were carried out for all rock samples. Firstly, the specimens were dried in the drying oven. Then, the samples were immersed in $\mathrm{HCl}$ solutions. Finally, put the sample and solution into the freeze-thaw tester shown in Figure 1 for freeze-thaw cycles. According to the China Meteorological Administration, the annual minimum temperature is about $-20^{\circ} \mathrm{C}$, and the maximum temperature is about $20^{\circ} \mathrm{C}$. Therefore, we set the freeze-thaw cycles temperature to $-20^{\circ} \mathrm{C}$. Each cycle lasted about 4 hours, and the number of cycles was 10 times. 

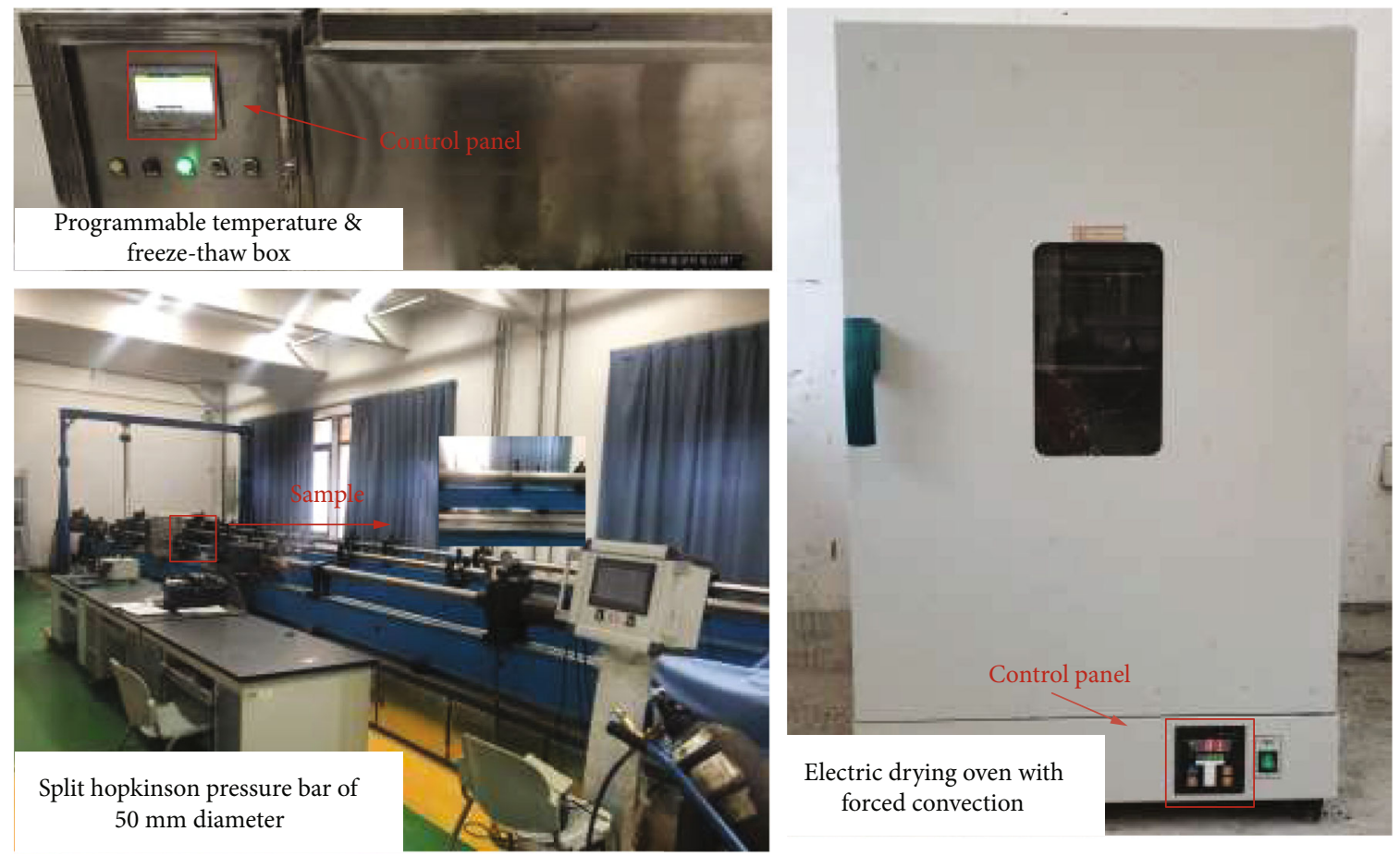

Figure 1: Experimental devices.

2.2. Test System. The split Hopkinson pressure bar (SHPB) device was the main test equipment. The variable crosssection SHPB test device with a diameter of $50 \mathrm{~mm}$ was adopted, as shown in Figure 2. The device consists of transmitter, pressure bar, energy absorption device, signal acquisition system, and signal processing system. The principle of the test was mainly to measure the incident wave, reflected wave, and transmission pulse in the transmission rod by using the strain gauge. Then, based on the assumption of one-dimensional stress wave and stress uniformity, the stress-strain relationship of the test sample was calculated by using the three-wave method in Equation (1) [32].

$$
\left\{\begin{array}{l}
\sigma=\frac{A}{2 A_{0}} E\left(\varepsilon_{i}+\varepsilon_{r}+\varepsilon_{t}\right), \\
\varepsilon=\frac{c_{0}}{l_{0}} \int_{0}^{t}\left(\varepsilon_{i}-\varepsilon_{r}-\varepsilon_{t}\right) d t, \\
\dot{\varepsilon}=\frac{c_{0}}{l_{0}}\left(\varepsilon_{i}-\varepsilon_{r}-\varepsilon_{t}\right),
\end{array}\right.
$$

where $E$ is Young's modulus of bars; $c_{0}$ is the elastic wave velocity in the pressure bar; $\varepsilon_{i}, \varepsilon_{r}$, and $\varepsilon_{t}$ are the strain in the bar corresponding to the incident wave, reflected wave, and transmitted wave, respectively; $l_{0}$ and $A_{0}$ are the original length and cross-sectional area of the sample, respectively; and $A$ is the cross-sectional area of the pressure bar.

2.3. Test Process. In the process of SHPB test, the prepared sample was taken out from the freeze-thaw test instrument and dried and then installed between the incident bar and the transmission bar to ensure that the sample was coaxial with the incident bar and the transmission bar. Subse- quently, the SHPB tests were carried out under four impact pressures (0.3 MPa, 0.4 MPa, 0.5 MPa, and 0.6 MPa). After the tests, the incident wave, reflected wave, and transmitted wave signals were recorded by the strain gauge.

Dynamic stress equilibrium is the premise to verify the validity of SHPB test [33]. It can be seen from Equation (2) that the dynamic force at the incident bar was proportional to the sum of the incident wave and the reflected wave, and the dynamic force at the transmission bar was proportional to the transmitted wave. Figure 3 shows the dynamic stress balance process of the concrete test. It could be found that the sum of the strains corresponding to the incident wave and the reflected wave was approximately equal to the strain corresponding to the transmitted wave, while the cross-sectional area and Young's modulus of the bar remained unchanged. Therefore, the test could meet the dynamic stress equilibrium.

$$
\left\{\begin{array}{l}
F_{1}=A E\left(\varepsilon_{i}+\varepsilon_{r}\right), \\
F_{2}=A E \varepsilon_{t},
\end{array}\right.
$$

where $F_{1}$ is the force on the incident bar and $F_{2}$ is the force on the transmission bar.

\section{Experimental Results and Analysis}

In order to reduce the dispersion, three effective tests were carried out under each test condition. According to the principle of SHPB test, the three-wave method is used for data processing. The average compressive strength, average elastic modulus, average strain rate, and other mechanical parameters of sandstone samples under different 


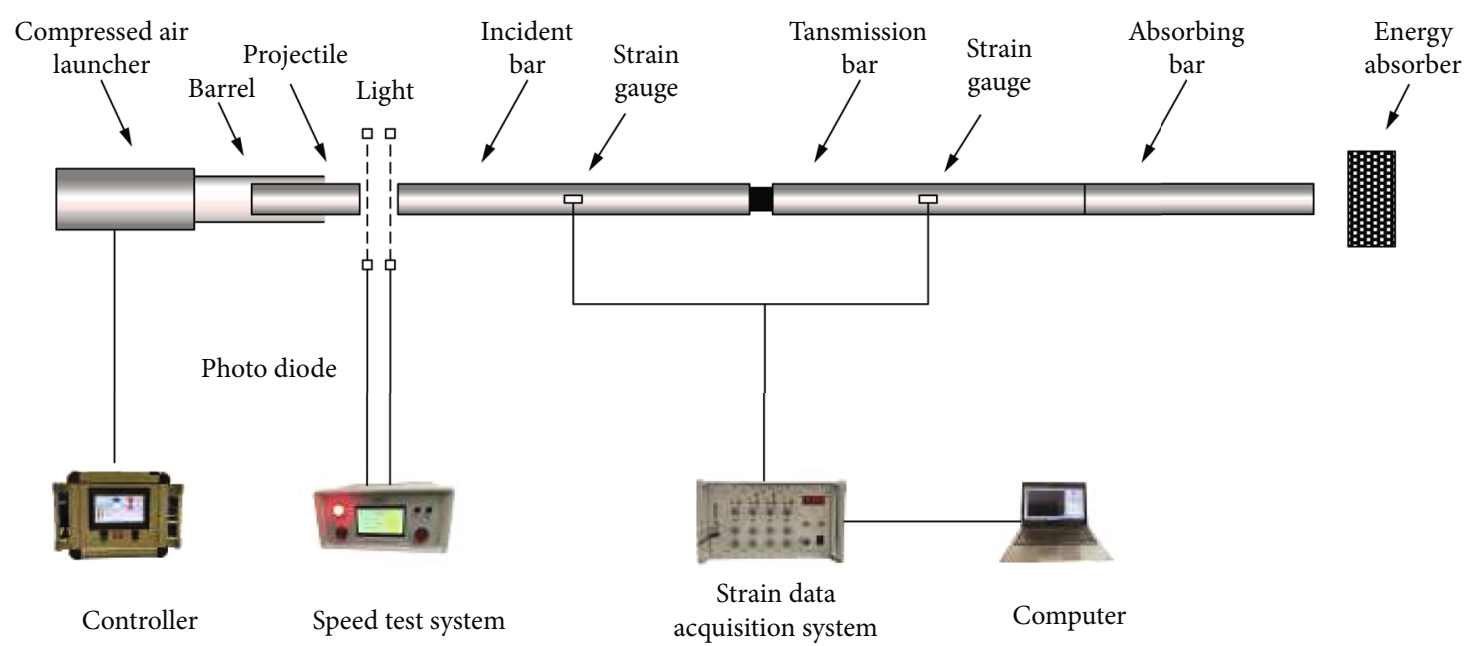

Figure 2: Split Hopkinson pressure bar of $50 \mathrm{~mm}$ diameter.

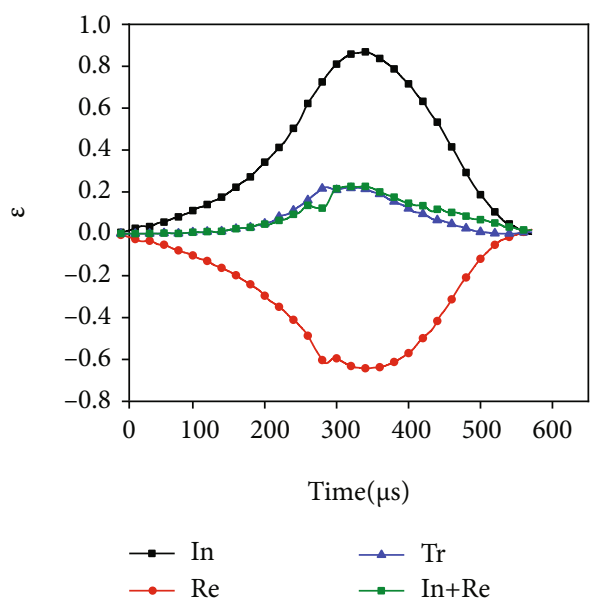

Figure 3: Strain balance check for a typical dynamic compression test.

concentrations of $\mathrm{HCl}$ solution and freeze-thaw cycle are obtained, as shown in Table 1.

3.1. Variation of Dynamic Stress-Strain Curves. The typical dynamic stress-strain curve of sandstone specimen is shown in Figure 4. Under the action of impact loads, sandstone mainly experienced the following deformation stages: (I) initial compaction stage, (II) linear elastic deformation stage, (III) plastic deformation stage, and (IV) failure stage.

Figure 5 shows the stress-strain curves of sandstone samples subjected to SHPB dynamic compression test under the coupling effect of $\mathrm{HCl}$ solutions with various concentrations and freeze-thaw cycles. Compared with Figure 3, it can be seen that variation characteristics of the stress-strain curves are as follows:

(1) The stress-strain curves of various concentrations of $\mathrm{HCl}$ solutions under freeze-thaw cycles had obvious compaction stages. When the $\mathrm{pH}$ value decreased from 7.0 to 1.1 , the compactness of the prepeak region increased gradually. As the $\mathrm{pH}$ value
TABLE 1: Test results of samples at different $\mathrm{pH}$ values and impact speeds.

\begin{tabular}{lcccccc}
\hline No. & $\mathrm{pH}$ & $v\left(\mathrm{~m} \cdot \mathrm{s}^{-1}\right)$ & $\dot{\varepsilon}\left(\mathrm{s}^{-1}\right)$ & $\sigma_{\mathrm{d}}(\mathrm{MPa})$ & $\varepsilon_{\mathrm{d}}\left(10^{-3}\right)$ & $E(\mathrm{GPa})$ \\
\hline 1 & 7.0 & 5.5 & 66.2 & 33.6 & 16.4 & 1.4 \\
2 & 7.0 & 6.0 & 89.5 & 34.1 & 16.9 & 1.3 \\
3 & 7.0 & 7.0 & 120.3 & 35.9 & 17.3 & 1.33 \\
4 & 7.0 & 7.8 & 133.5 & 38.5 & 17.9 & 1.5 \\
5 & 5.8 & 5.5 & 71.8 & 32.8 & 17.5 & 1.08 \\
6 & 5.8 & 6.0 & 97.1 & 33.3 & 18.1 & 1.22 \\
7 & 5.8 & 7.0 & 107.7 & 35.0 & 18.7 & 1.23 \\
8 & 5.8 & 7.8 & 142.6 & 37.4 & 19.1 & 1.28 \\
9 & 3.2 & 5.5 & 68.4 & 30.1 & 19.9 & 0.87 \\
10 & 3.2 & 6.0 & 86.6 & 31.9 & 20.6 & 0.91 \\
11 & 3.2 & 7.0 & 118.3 & 34.1 & 21.0 & 1.05 \\
12 & 3.2 & 7.8 & 147.7 & 37.1 & 22.1 & 0.99 \\
13 & 1.1 & 5.5 & 75.9 & 28.8 & 22.4 & 0.76 \\
14 & 1.1 & 6.0 & 93.1 & 30.9 & 23.6 & 0.78 \\
15 & 1.1 & 7.0 & 115.3 & 33.3 & 24.3 & 0.75 \\
16 & 1.1 & 7.8 & 145.6 & 36.2 & 25.0 & 0.80 \\
\hline
\end{tabular}

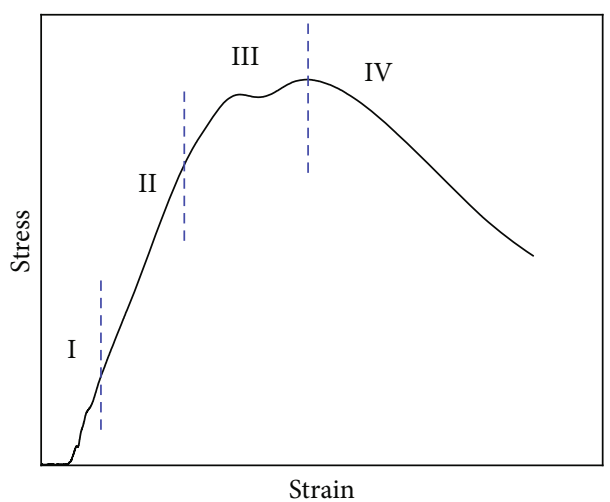

Figure 4: Typical dynamic stress-strain curve. 


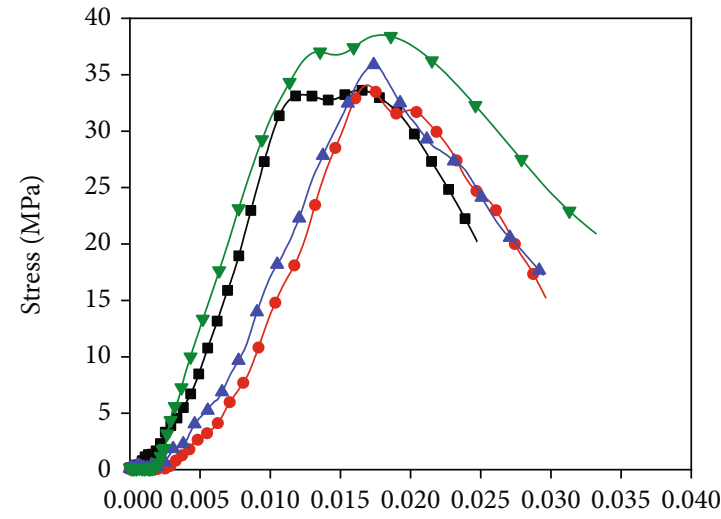

Strain

$$
\begin{array}{ll}
\multimap \dot{\varepsilon}=66.2 \mathrm{~s}^{-1} & \longrightarrow \dot{\varepsilon}=120.3 \mathrm{~s}^{-1} \\
\multimap \dot{\varepsilon}=89.5 \mathrm{~s}^{-1} & \rightarrow \dot{\varepsilon}=133.5 \mathrm{~s}^{-1}
\end{array}
$$

(a) $0 \mathrm{~mol} \cdot \mathrm{L}^{-1} \mathrm{HCl} \mathrm{pH}=7.0$

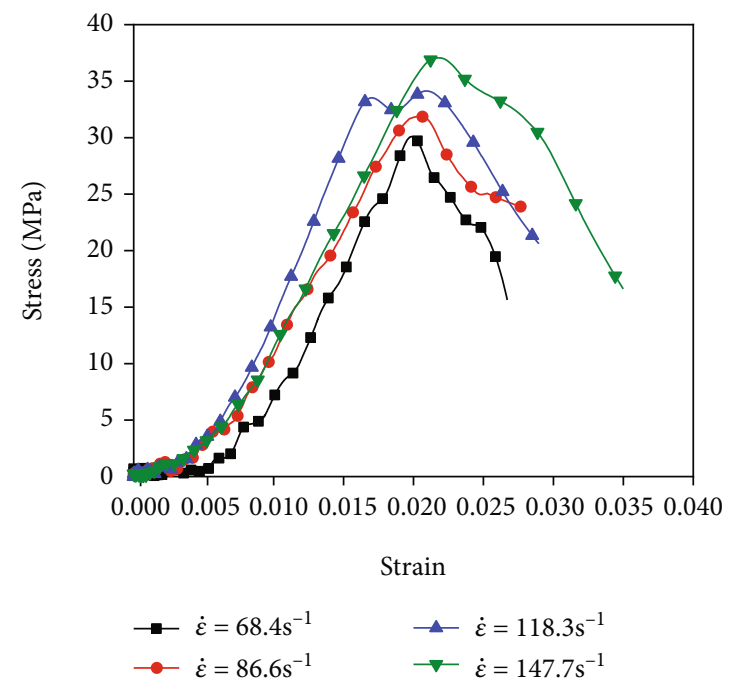

(c) $0.1 \mathrm{~mol} \cdot \mathrm{L}^{-1} \mathrm{HCl} \mathrm{pH}=3.2$

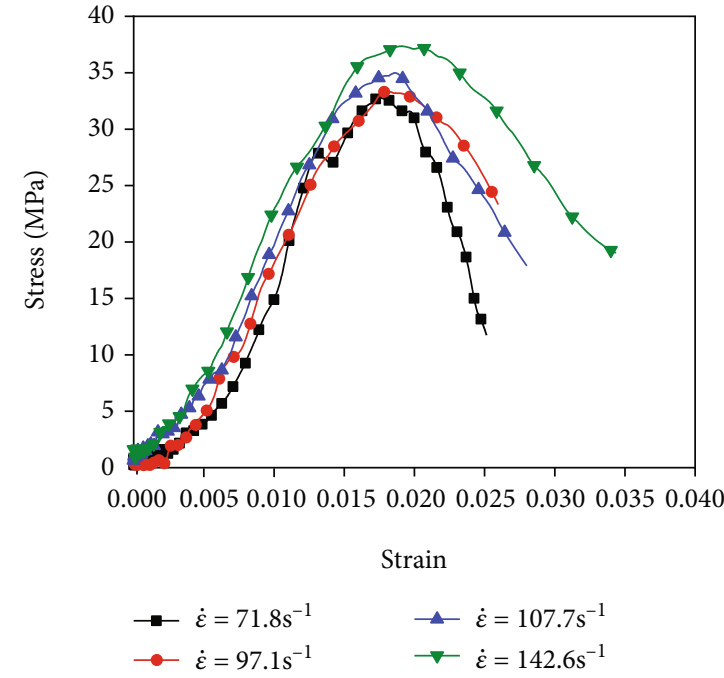

(b) $0.01 \mathrm{~mol} \cdot \mathrm{L}^{-1} \mathrm{HCl} \mathrm{pH}=5.8$

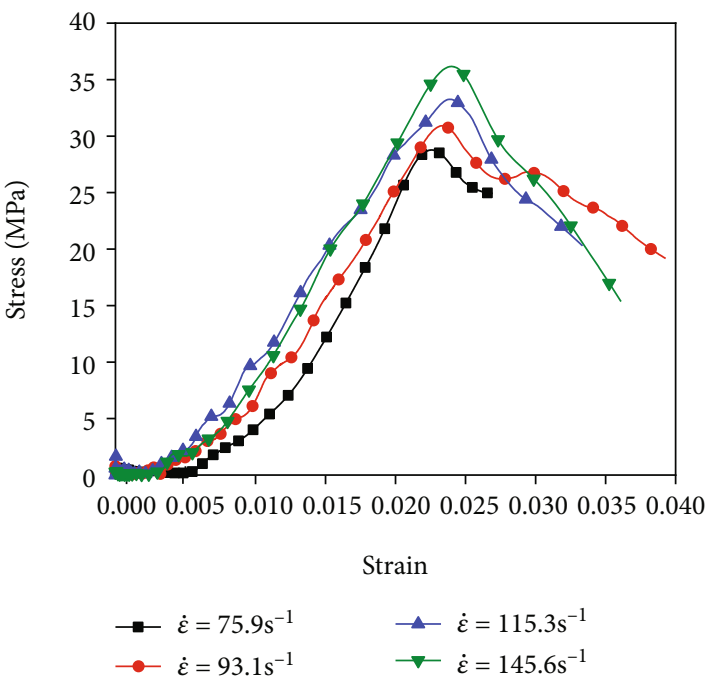

(d) $1 \mathrm{~mol} \cdot \mathrm{L}^{-1} \mathrm{HCl} \mathrm{pH}=1.1$

Figure 5: The dynamic stress-strain curves of the specimens with variation concentrations of hydrochloric acid solution affected by variation loading rates.

decreased, the internal corrosion of the sandstone increased. And the pores and fissures gradually expanded, which further increased the degree of compaction

(2) The stress-strain curves of each concentration of $\mathrm{HCl}$ solution had obvious linear elastic stages. In the prepeak region, the proportion of linear elastic deformation decreased to a certain extent with the increase of the solution concentration. When the $\mathrm{pH}$ value was 1.1, the proportion was the smallest. Thus, with the decrease of $\mathrm{pH}$ value, the influence of impact loads on the linear elastic deformation of sandstone became smaller

3.2. Variation of Dynamic Compressive Strength. Figure 6 shows the spatial surface characterizing the compressive strength $\sigma_{\mathrm{d}}$ to describe the coupling effect of $\mathrm{pH}$ and strain rate on the compressive strength. It can be seen from the figure that $\sigma_{\mathrm{d}}$ is positively correlated with the $\mathrm{pH}$ value and also positively correlated with strain rate. Figure 7 shows the relationship between the dynamic compressive strength of sandstone samples with the $\mathrm{pH}$ value and strain rate under the coupling effect of different concentrations of $\mathrm{HCl}$ solutions and freeze-thaw cycles. It can be found that

(1) The dynamic compressive strength of sandstone samples increased with the increase of strain rate under the coupling effect of the same concentration of $\mathrm{HCl}$ solution and freeze-thaw cycle. At $\mathrm{pH}$ of 7.0 , as the strain rate increased from $66.2 \mathrm{~s}^{-1}$ to $133.45 \mathrm{~s}^{-1}$, the compressive strength increased by $14.6 \%$. At $\mathrm{pH}$ of 1.1, as the strain rate increased from $75.85 \mathrm{~s}^{-1}$ to $145.6 \mathrm{~s}^{-1}$, the compressive strength increased by $25.7 \%$. Equation (3) shows the linear fitting relationship of compressive strength with 


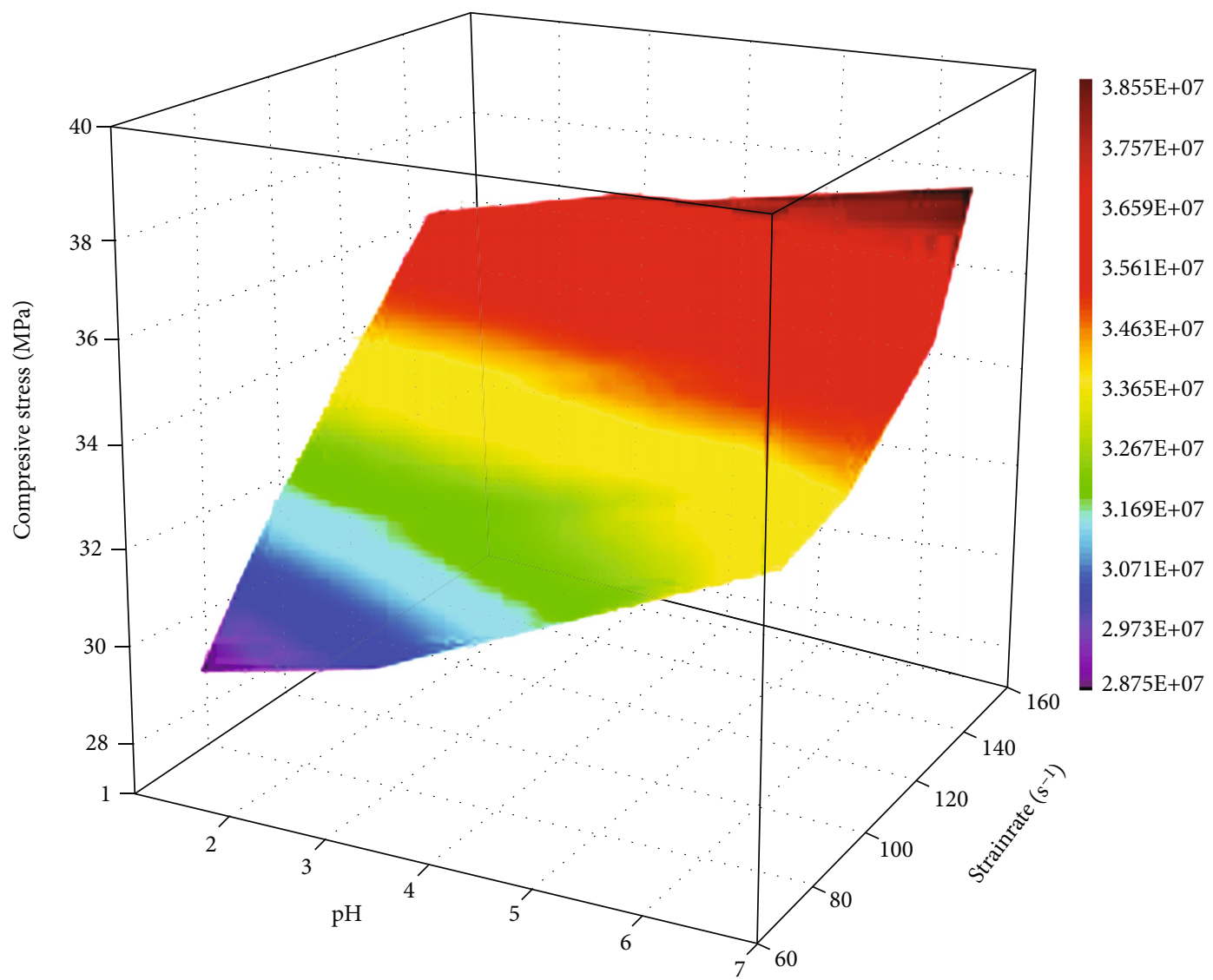

FIGURE 6: Coupling effect of the $\mathrm{pH}$ value and strain rate on compressive strength.

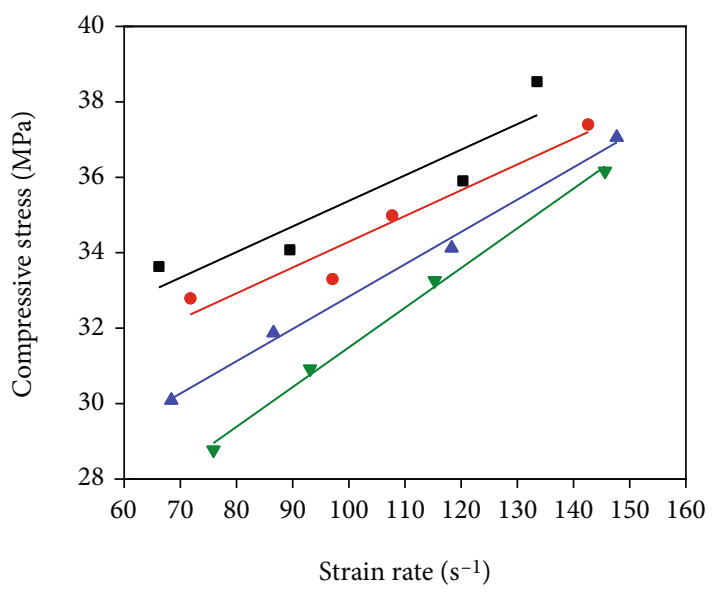

$$
\begin{array}{ll}
\text { - } \mathrm{pH}=7.0 & \Delta \mathrm{pH}=3.2 \\
\text { - } \mathrm{pH}=5.8 & \nabla \mathrm{pH}=1.1
\end{array}
$$

(a) Effect of strain rate on compressive strength under different $\mathrm{pH}$ values

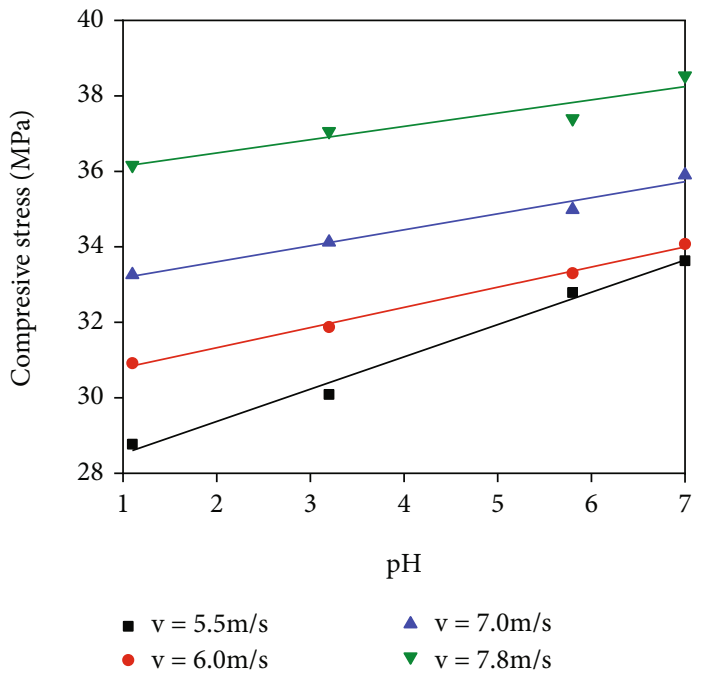

(b) Effect of $\mathrm{pH}$ value on compressive strength under different strain rates

FIGURE 7: Variation curves of compressive strength.

strain rate. As the $\mathrm{pH}$ value of the solution decreased, the slope of the linear fitting equation gradually increased. It showed that the dynamic compressive strength of sandstone samples became more sensitive to strain rate as the $\mathrm{pH}$ value decreased
(2) As the $\mathrm{pH}$ value of the $\mathrm{HCl}$ solution decreased, the dynamic compressive strength of the sample decreased successively. Specifically, when the strain rate is in the range of $66.2 \mathrm{~s}^{-1}$ to $75.9 \mathrm{~s}^{-1}$, the compressive strength increased by $16.9 \%$ with the increase of $\mathrm{pH}$ value from 1.1 to 7.0 . When the strain 
rate is in the range of $133.5 \mathrm{~s}^{-1}$ to $147.7 \mathrm{~s}^{-1}$, the compressive strength increased by $6.6 \%$ with the increase of $\mathrm{pH}$ value from 1.1 to 7.0. Equation (4) shows the linear fitting relationship of compressive strength with the $\mathrm{pH}$ value. As the strain rate increased, the slope of the linear fitting equation gradually increased. It showed that the dynamic compressive strength of sandstone samples became less sensitive to the $\mathrm{pH}$ value as the strain rate increased

$$
\begin{gathered}
\sigma_{d}= \begin{cases}2.86 \times 10^{7}+6.79 \times 10^{4} \dot{\varepsilon}, & R^{2}=0.86, \\
2.75 \times 10^{7}+6.83 \times 10^{4} \dot{\varepsilon}, & R^{2}=0.93, \\
2.43 \times 10^{7}+8.57 \times 10^{4} \dot{\varepsilon}, & R^{2}=0.99, \\
2.24 \times 10^{7}+10.52 \times 10^{4} \dot{\varepsilon}, & R^{2}=0.99,\end{cases} \\
\sigma_{d}= \begin{cases}2.77 \times 10^{7}+8.55 \times 10^{4} \mathrm{pH}, & R^{2}=0.99, \\
3.03 \times 10^{7}+5.34 \times 10^{4} \mathrm{pH}, & R^{2}=0.99, \\
3.28 \times 10^{7}+4.25 \times 10^{4} \mathrm{pH}, & R^{2}=0.98, \\
3.58 \times 10^{7}+3.52 \times 10^{4} \mathrm{pH}, & R^{2}=0.90 .\end{cases}
\end{gathered}
$$

3.3. Variation of Dynamic Peak Strain. Figure 8 shows the spatial surface characterizing the peak strain $\varepsilon_{\mathrm{d}}$ to describe the coupling effect of $\mathrm{pH}$ and strain rate on the peak strain. It can be seen from the figure that $\varepsilon_{\mathrm{d}}$ is positively correlated with strain rate and negatively correlated with $\mathrm{pH}$. Figure 9 shows the relationship between peak strain and strain rate of sandstone samples under different concentrations of $\mathrm{HCl}$ solutions coupled with freeze-thaw cycles. It can be found that

(1) Equation (5) is the linear fitting relationship between the peak strain and the strain rate. It can be seen that the strain rate had a certain influence on the peak strain of the sample under the coupling effect of different concentrations of $\mathrm{HCl}$ solutions and freezethaw cycles. With the increase of strain rate, the peak strain of each concentration increased linearly. When $\mathrm{pH}=7.0$, as the strain rate increased from $66.2 \mathrm{~s}^{-1}$ to $133.45 \mathrm{~s}^{-1}$, the peak strain increased by 9.1\%; When $\mathrm{pH}=1.1$, as the strain rate increased from $75.85 \mathrm{~s}^{-1}$ to $145.6 \mathrm{~s}^{-1}$, the peak strain increased by $11.6 \%$. It showed that as the $\mathrm{pH}$ value decreased, the sensitivity of peak strain to strain rate increased

(2) The dynamic peak strain of the sample decreased with the increase of the $\mathrm{pH}$ value of $\mathrm{HCl}$ solution. When the strain rate is in the range of $66.2 \mathrm{~s}^{-1}$ to $75.9 \mathrm{~s}^{-1}$, the peak strain decreased by $26.7 \%$ with the increase of $\mathrm{pH}$ value from 1.1 to 7.0 . When the strain rate is in the range of $133.5 \mathrm{~s}^{-1}$ to $147.7 \mathrm{~s}^{-1}$, the peak strain decreased by $28.4 \%$ with the increase of $\mathrm{pH}$ value from 1.1 to 7.0. Equation (6) shows the linear fitting relationship of peak strain with the $\mathrm{pH}$ value. As the strain rate increased, the slope of the linear fitting equation gradually increased. The results show that the dynamic peak strain of sandstone samples became more sensitive to the $\mathrm{pH}$ value at a high strain rate. In addition, as the strain rate increases, the increase rate of the slope of the fitting equation gradually decreases and finally tends to $-1.14$

$$
\begin{gathered}
\varepsilon_{d}= \begin{cases}1.50 \times 10^{-2}+2.13 \times 10^{-5} \dot{\varepsilon}, & R^{2}=0.94, \\
1.59 \times 10^{-2}+2.28 \times 10^{-5} \dot{\varepsilon}, & R^{2}=0.95, \\
1.82 \times 10^{-2}+2.57 \times 10^{-5} \dot{\varepsilon}, & R^{2}=0.96, \\
1.99 \times 10^{-2}+3.57 \times 10^{-5} \dot{\varepsilon}, & R^{2}=0.92,\end{cases} \\
\varepsilon_{d}= \begin{cases}2.36 \times 10^{-2}-1.05 \times 10^{-3} \mathrm{pH}, & R^{2}=0.99, \\
2.46 \times 10^{-2}-1.12 \times 10^{-3} \mathrm{pH}, & R^{2}=0.99, \\
2.51 \times 10^{-2}-1.14 \times 10^{-3} \mathrm{pH}, & R^{2}=0.98, \\
2.61 \times 10^{-2}-1.14 \times 10^{-3} \mathrm{pH}, & R^{2}=0.99 .\end{cases}
\end{gathered}
$$

3.4. Variation of Dynamic Modulus of Elasticity. In order to describe the coupling relationship between the $\mathrm{pH}$ value and strain rate on elastic modulus, Figure 10 shows the spatial surface characterizing elastic modulus $E$. It can be seen from the figure that $E$ is linearly correlated with the $\mathrm{pH}$ value and shows certain nonlinear characteristics with strain rate. Figure 11 shows the relationship between dynamic modulus of elasticity and strain rate of sandstone samples under different concentrations of $\mathrm{HCl}$ solutions and freeze-thaw cycles.

(1) When the the $\mathrm{pH}$ value was 7.0, the dynamic elastic modulus first decreased and then increased with the increase of strain rate. When the $\mathrm{pH}$ value decreased from 5.8 to 1.1 , the dynamic elastic modulus varied little with the increase of strain rate. Therefore, the strain rate had no obvious effect on the dynamic elastic modulus under the coupling effect of different concentrations of $\mathrm{HCl}$ solutions and freeze-thaw cycles

(2) With the decrease of the $\mathrm{pH}$ value, the dynamic elastic modulus decreased obviously. Equation (7) shows the linear fitting relationship of elastic modulus with $\mathrm{pH}$ value. As the strain rate increased, the slope of linear fitting equation first decreases and then increases. When the strain rate ranges from $66.2 \mathrm{~s}^{-1}$ to $75.9 \mathrm{~s}-1,86.6 \mathrm{~s}^{-1}$ to $97.1 \mathrm{~s}^{-1}, 107.7 \mathrm{~s}^{-1}$ to $120.3 \mathrm{~s}^{-1}$, and $133.5 \mathrm{~s}^{-1}$ to $147.7 \mathrm{~s}^{-1}$, the elastic modulus increased by $83.7 \%, 67.6 \%, 78.4 \%$, and $87.9 \%$ respectively, with the increase of the $\mathrm{pH}$ value from 1.1 to 7.0. The results show that when the strain rate ranges from $86.6 \mathrm{~s}-1$ to $97.1 \mathrm{~s}-1$, the sensitivity of dynamic elastic modulus to $\mathrm{pH}$ value is the lowest. After that, with the increase of strain rate, the sensitivity of dynamic elastic modulus to the $\mathrm{pH}$ value increased 


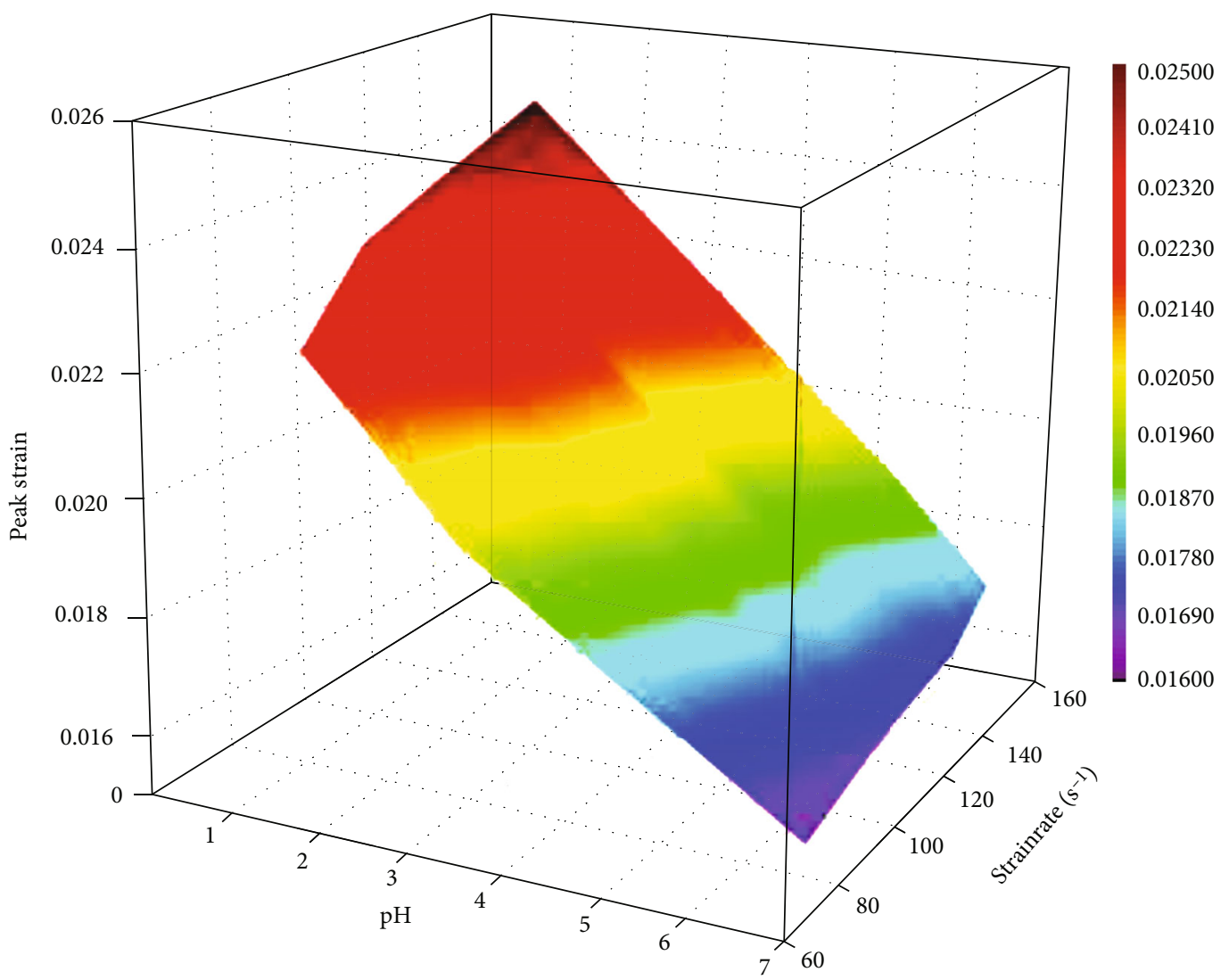

FIGURE 8: Coupling effect of $\mathrm{pH}$ value and strain rate on peak strain.
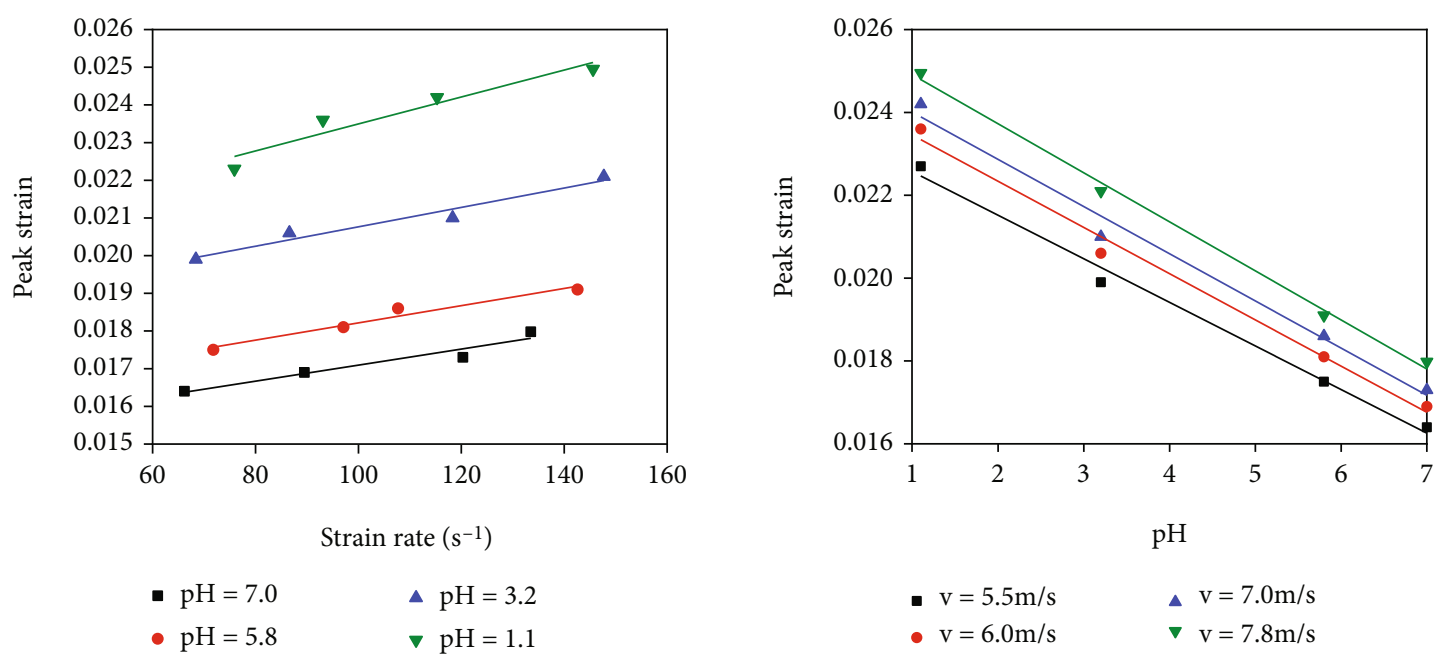

(a) Effect of strain rate on peak strain under different $\mathrm{pH}$ values

(b) Effect of $\mathrm{pH}$ value on peak strain under different strain rates

FIgURE 9: Variation curves of peak strain.

$$
E= \begin{cases}5.98 \times 10^{8}+1.01 \times 10^{8} \mathrm{pH}, & R^{2}=0.89, \\ 6.55 \times 10^{8}+9.36 \times 10^{7} \mathrm{pH}, & R^{2}=0.98, \\ 6.8 \times 10^{8}+9.53 \times 10^{7} \mathrm{pH}, & R^{2}=0.97 \\ 6.46 \times 10^{8}+1.16 \times 10^{8} \mathrm{pH}, & R^{2}=0.98\end{cases}
$$

\section{Mesomechanism of Dynamic Mechanical Properties of Sandstone}

The above test results showed that the strength and deformation characteristics of sandstones changed significantly under the coupling effect of different concentrations of $\mathrm{HCl}$ solutions 


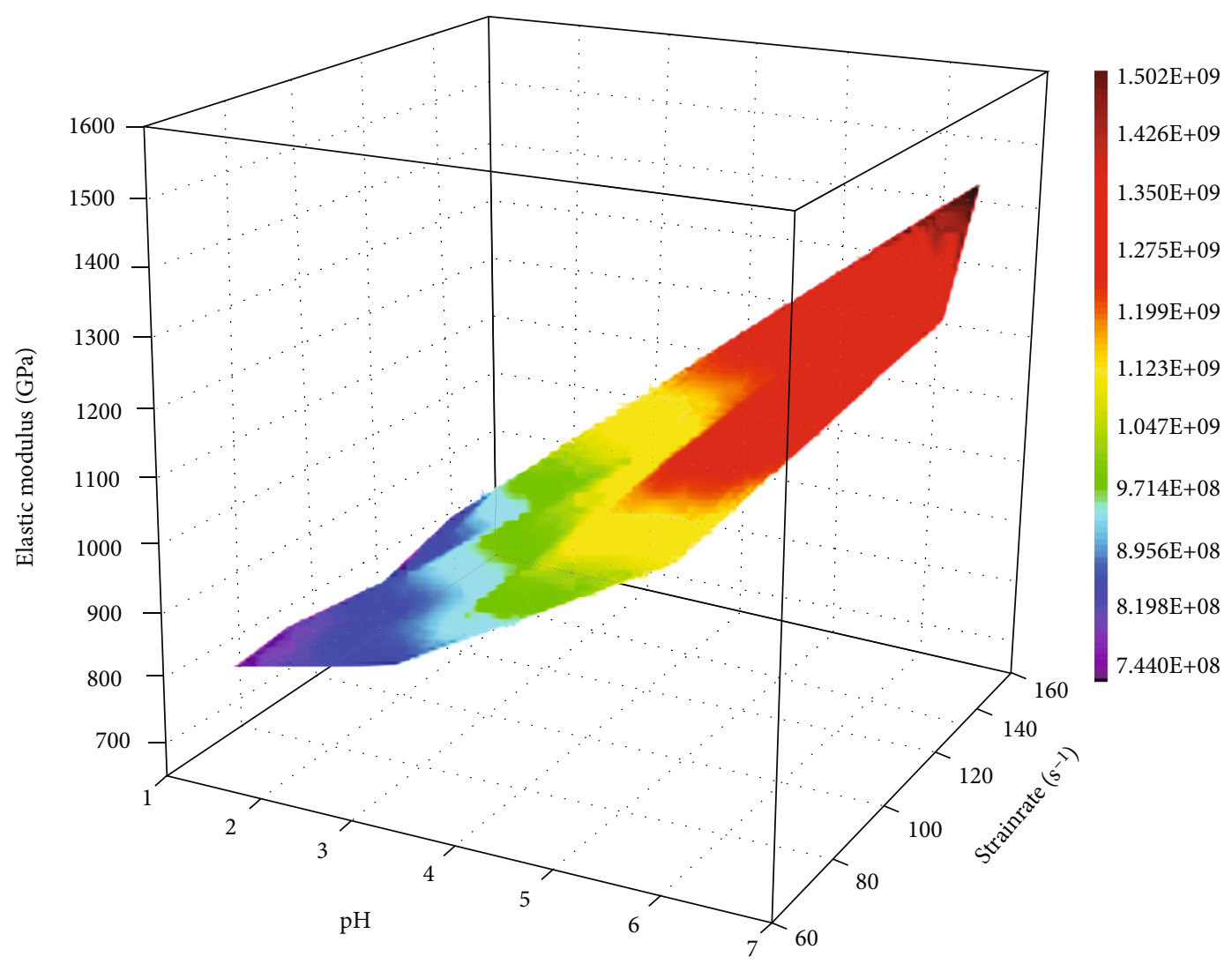

FIGURE 10: Coupling effect of $\mathrm{pH}$ value and strain rate on elastic modulus.

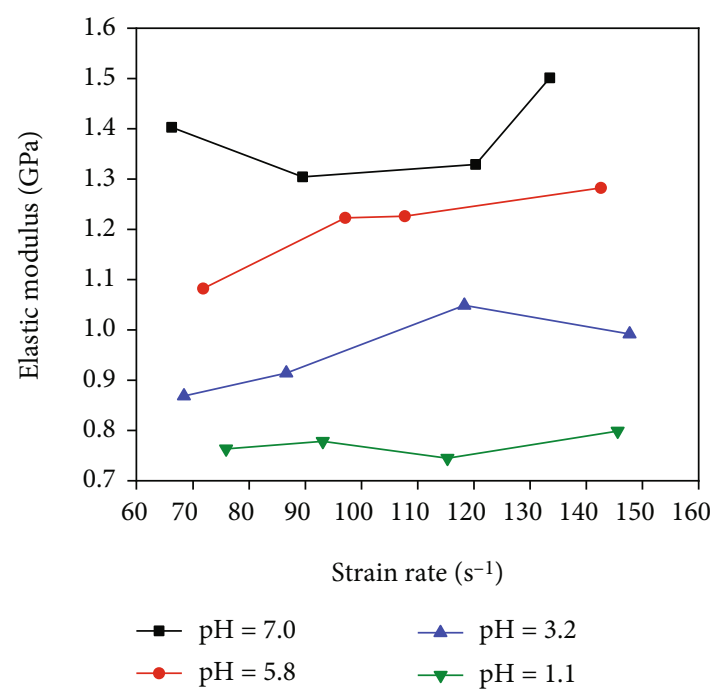

(a) Effect of strain rate on elastic modulus under different $\mathrm{pH}$ values

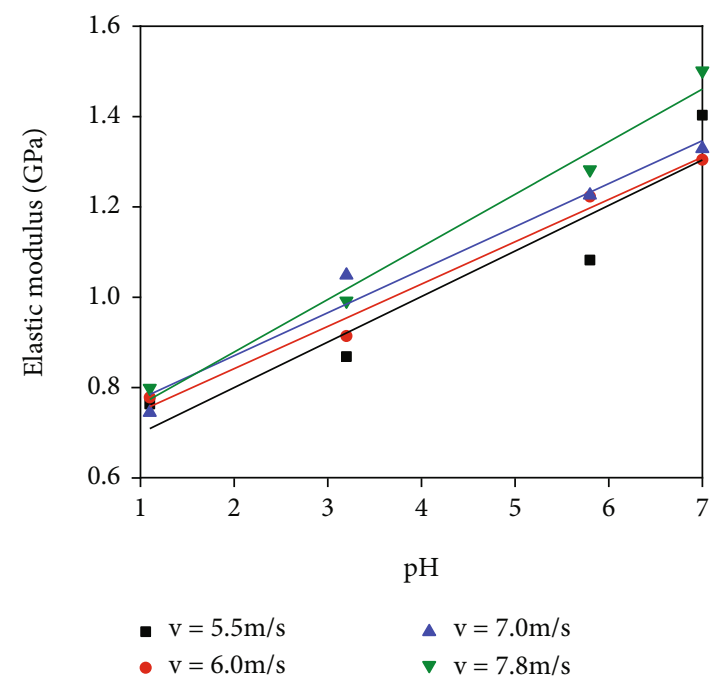

(b) Effect of $\mathrm{pH}$ value on elastic modulus under different strain rates

Figure 11: Variation curves of elastic modulus.

and freeze-thaw cycles, and the damage evolution of rock material mechanical properties was closely related to the change of microstructure. Therefore, in order to accurately analyze the hydrochemical effect, X-ray diffractometer (XRD) and scanning electron microscopy (SEM) were used to confirm the changes of mineral composition and microstructure damage of samples, so as to verify the change law of rock mechanical properties.
4.1. Variation Law of Sandstone Composition. In order to determine the influence of $\mathrm{HCl}$ solution on the composition change of sandstone, $\mathrm{X}$-ray diffraction was used to analyze the samples. Figure 12 shows the $\mathrm{X}$-ray diffraction pattern of the sandstone corroded by various concentrations of $\mathrm{HCl}$ solutions. The main components of the samples in this test are quartz, kaolinite, and muscovite. Figure 13 shows the 


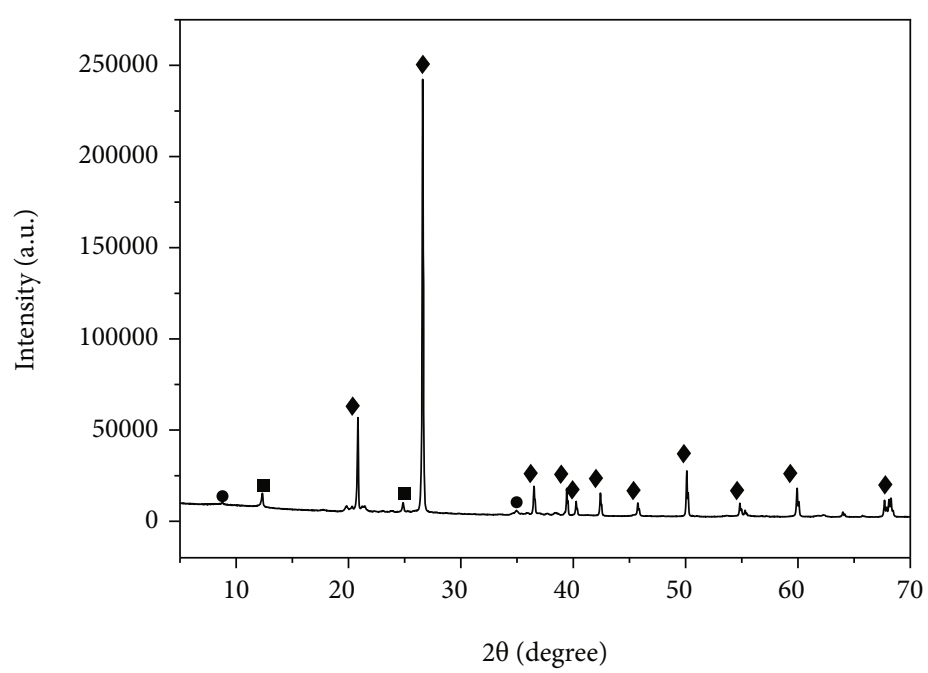

(a) $0 \mathrm{~mol} \cdot \mathrm{L}^{-1} \mathrm{pH}=7.2$

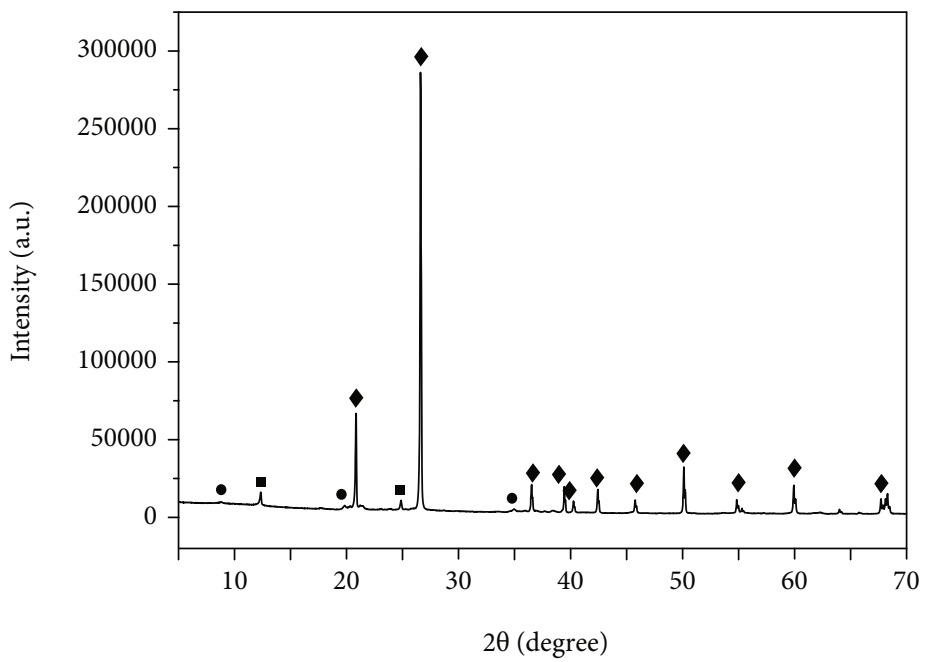

(b) $0.01 \mathrm{~mol} \cdot \mathrm{L}^{-1} \mathrm{pH}=5.6$

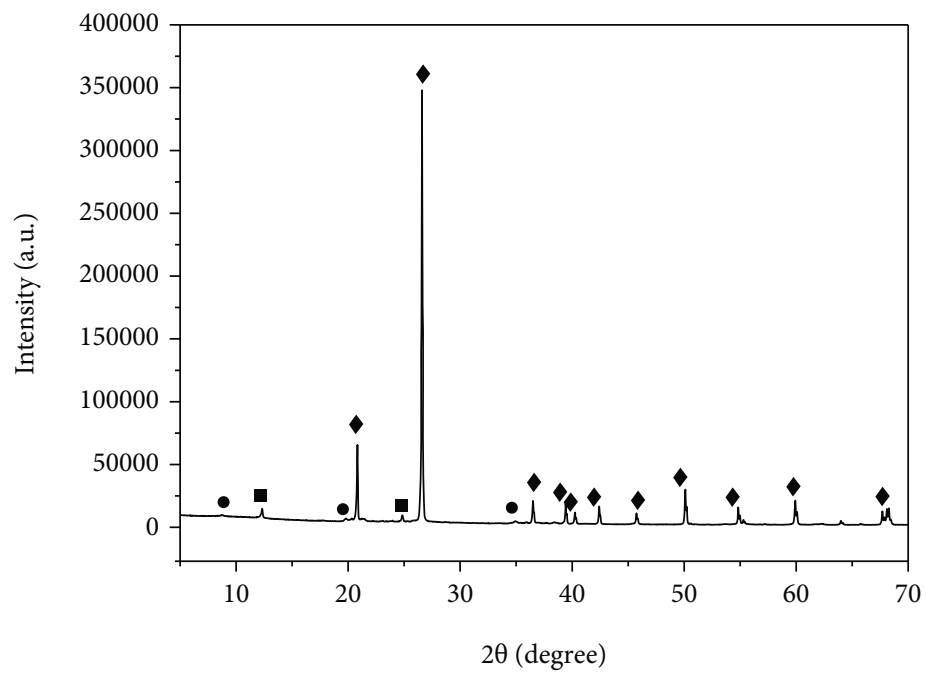

(c) $0.1 \mathrm{~mol} \cdot \mathrm{L}^{-1} \mathrm{pH}=3.2$

Figure 12: Continued. 


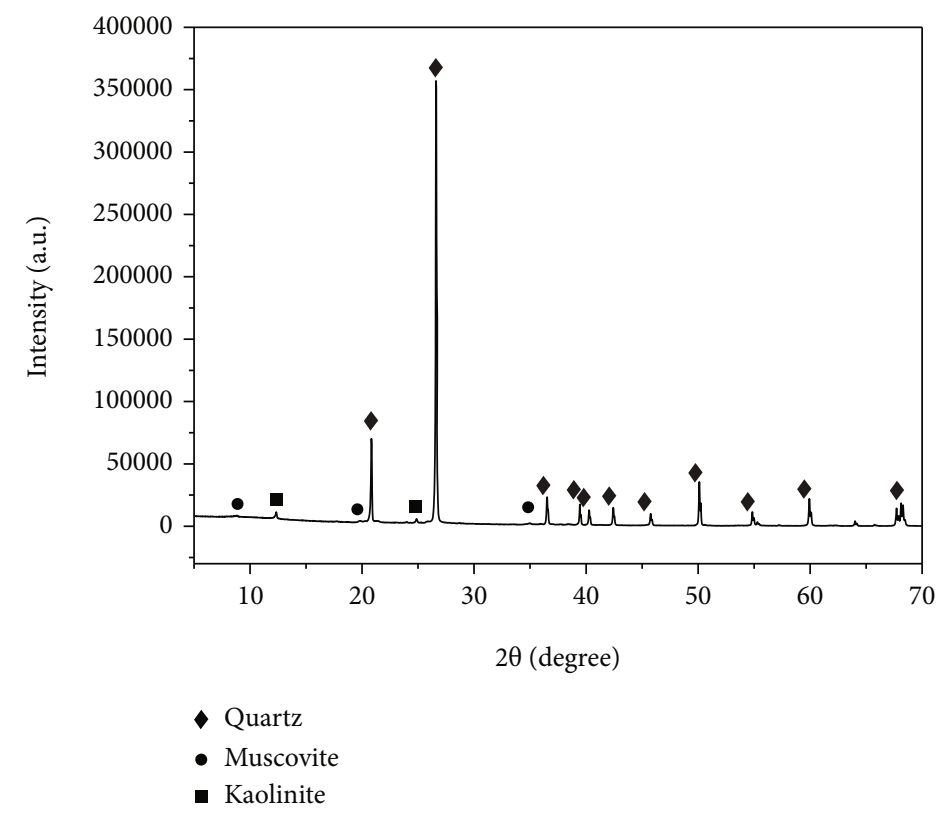

(d) $1 \mathrm{~mol} \cdot \mathrm{L}^{-1} \mathrm{pH}=1.1$

FIgURE 12: Mass fraction of sandstone component as it varies with the solution concentration.

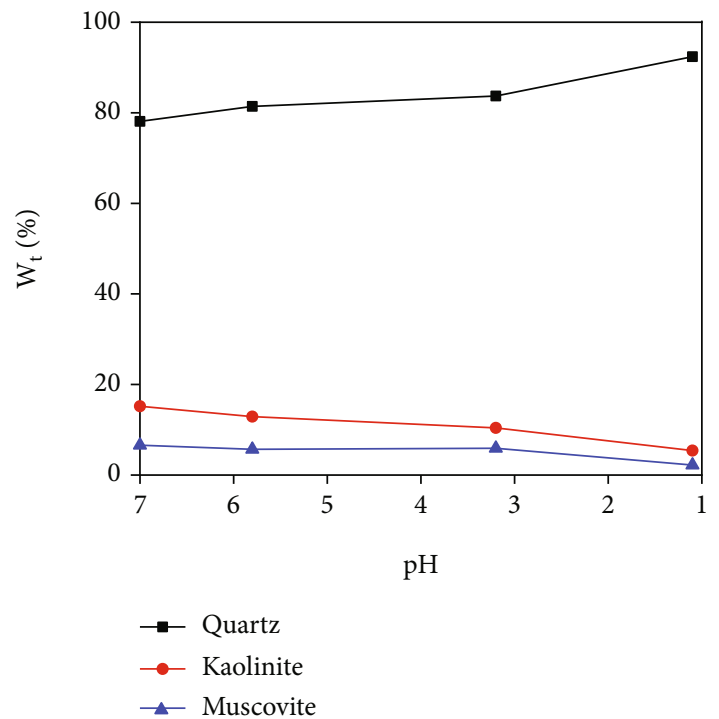

FIGURE 13: Variation curves of main mineral components with $\mathrm{pH}$ value.

variations of mineral composition $W_{\mathrm{t}}$ with $\mathrm{pH}$ value. The results are as follows.

The $\mathrm{pH}$ value of solution, the composition of solute, and the internal structure of rock are the main factors affecting the chemical corrosion of rock. In this paper, $\mathrm{HCl}$ solution is used to affect the chemical corrosion of the same sandstone after the same number of times. Therefore, the $\mathrm{pH}$ value of the solution is the main reason affecting the chemical corrosion of rocks. According to the XRD test results, the main components of the main possible chemical reactions of various mineral components in sandstone affected by $\mathrm{HCl}$ solution are shown in formula (8)-(11), which can be found in Liu et al. [34] and Lin et al. [35].

(1) The content of quartz in the sandstone was much greater than other mineral compositions, and $78.1 \%$ was in distilled water. In the range of $\mathrm{pH} 7.0$ to 3.2 , quartz content was relatively stable, showing a gradual upward trend. It increased from $78.1 \%$ to $83.7 \%$, with a growth rate of $7.17 \%$. When the $\mathrm{pH}$ value decreased to 1.1 , it rose sharply from $83.7 \%$ to $92.4 \%$, with the increase rate of $10.39 \%$. The above situations might be caused by the hydrochemical reaction of quartz in distilled water and $\mathrm{HCl}$ solution:

$$
\begin{array}{r}
\mathrm{SiO}_{2}+\mathrm{H}_{2} \mathrm{O} \longrightarrow \mathrm{H}_{4} \mathrm{SiO}_{4} \\
\mathrm{SiO}_{2}+\mathrm{H}^{+} \longrightarrow \mathrm{Si}^{4+}+2 \mathrm{H}_{2} \mathrm{O}
\end{array}
$$

(2) Kaolinite was one of the main mineral content, and $15.2 \%$ was in distilled water. With the decrease of $\mathrm{pH}$ value, the content of kaolinite decreased gradually. In the range of $\mathrm{pH} 7.0$ to 3.2 , it decreased from $15.2 \%$ to $10.4 \%$, and the rate of decline was $31.58 \%$. When the $\mathrm{pH}$ value decreased to 1.1 , it decreased from $10.4 \%$ to $5.4 \%$, with a decrease rate of $48.08 \%$. The results showed that when the $\mathrm{pH}$ value decreased to 1.1 , the content of kaolinite decreased significantly. The following chemical reactions occurred in kaolinite affected by $\mathrm{HCl}$ solution: 


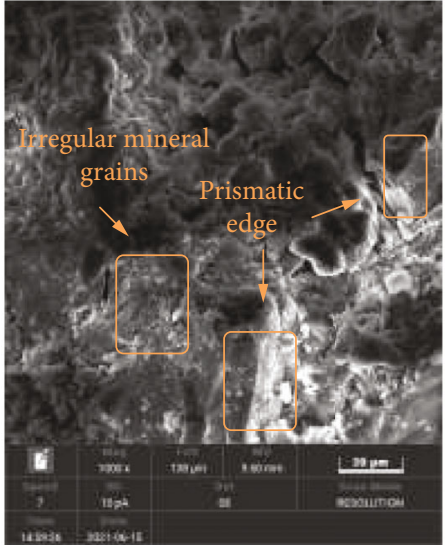

(a) Sandstone-natural state

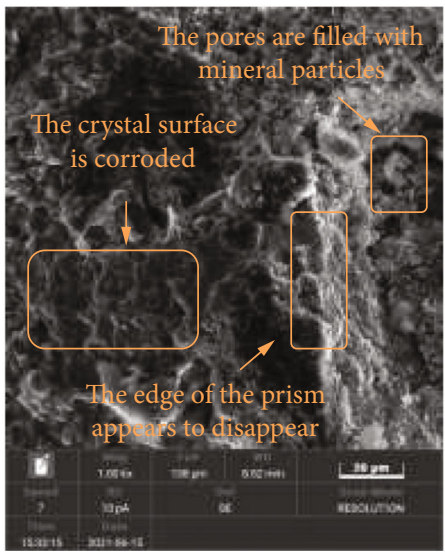

(c) Sandstone $-\mathrm{pH}=5.8, \mathrm{~F}-\mathrm{T}$ cycles

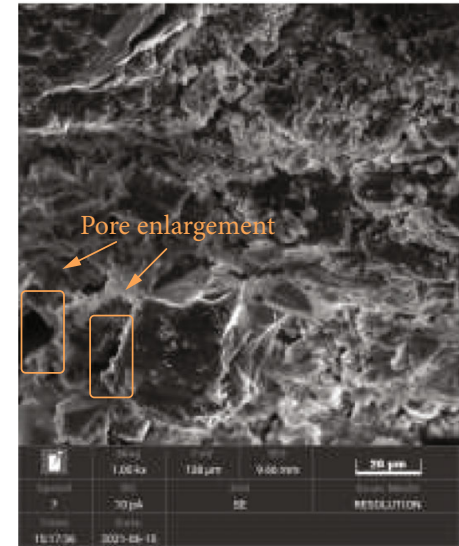

(b) Sandstone-F-T cycles

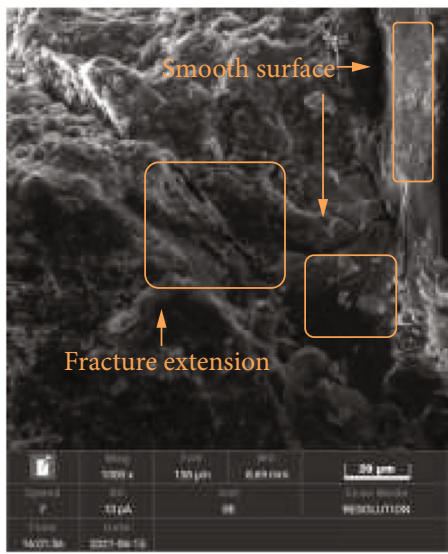

(d) Sandstone $-\mathrm{pH}=3.2, \mathrm{~F}-\mathrm{T}$ cycles

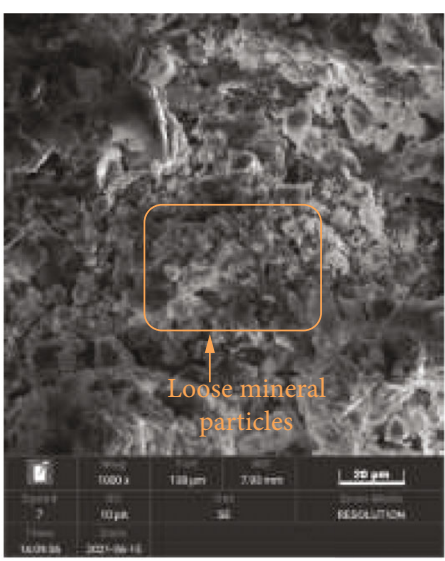

(e) Sandstone $-\mathrm{pH}=1.1, \mathrm{~F}-\mathrm{T}$ cycles

FIGURE 14: Sandstone microscopic images under different test conditions.

$\mathrm{Al}_{2} \mathrm{Si}_{2} \mathrm{O}_{5}(\mathrm{OH})_{4}+6 \mathrm{H}^{-} \longrightarrow 2 \mathrm{Al}^{3+}+2 \mathrm{SiO}_{2}+5 \mathrm{H}_{2} \mathrm{O}$

(3) The content of muscovite occupied the third place of the main mineral content, and $6.6 \%$ was in distilled water. Similarly, within the $\mathrm{pH}$ range of 7.0 to 3.2 , the content of muscovite had little change, showing a slow downward trend. When the $\mathrm{pH}$ value decreased to 1.1 , it decreased significantly from $5.9 \%$ to $2.2 \%$, with a decrease rate of $62.71 \%$. The following chemical reactions occurred in muscovite affected by $\mathrm{HCl}$ solution:

$$
\mathrm{KAl}_{3} \mathrm{Si}_{3} \mathrm{O}_{10}(\mathrm{OH})_{2}+10 \mathrm{H}^{-}=3 \mathrm{Al}^{3+}+3 \mathrm{SiO}_{2}+\mathrm{K}^{+}+6 \mathrm{H}_{2} \mathrm{O}
$$


Under the operation of freeze-thaw cycles, $\mathrm{HCl}$ solution has a considerable effect on sandstone samples. The fundamental reason for this is because during the freezing process, the solution in the pores expands after reaching the freezing point, causing pore fractures to form, and the expansion coefficients of mineral particles differ. It is also the cause of pore crack propagation. The contact area between the $\mathrm{HCl}$ solution and the mineral particles is increased after dissolution owing to the widening of pore fissures, and the chemical damaging impact is intensified. The sample is mainly composed of quartz, kaolinite, and muscovite. The chemical properties of quartz were relatively stable, and the hydrochemical effect was not obvious. With the increase of the concentration of $\mathrm{HCl}$ solution, the proportion of quartz content showed an increasing trend. Therefore, it could be seen that the hydrochemical reaction of quartz in distilled water and $\mathrm{HCl}$ solution was not the main factor for the significant change in its content. According to Equations (10) and (11), kaolinite and muscovite gradually decomposed and produced free $\mathrm{SiO}_{2}$ particles under the corrosion of $\mathrm{HCl}$ solution. With the progress of hydrochemical reaction, the proportion of kaolinite and muscovite gradually decreased, and free $\mathrm{SiO}_{2}$ particles were produced, making the proportion of quartz increase. With the deepening of hydrochemical reaction, the pore structure of the sandstone sample was destroyed, and the cementation between internal minerals became weak. With the decrease of $\mathrm{pH}$ value, the hydrochemical effect was strengthened, especially when the $\mathrm{pH}$ value decreased from 3.2 to 1.1. It showed that the mesomechanism of sandstone sample was consistent with the mechanism of mechanical properties.

4.2. Variation Law of Sandstone Microstructure. Mineral particles, cements, and pores are the fundamental components of rocks, and they also govern the macroscopic mechanical characteristics of rocks. The microstructure properties of sandstone were acquired using scanning electron microscope study of sandstone samples, as illustrated in Figure 14. The interior microstructure of the sample had changed significantly as a result of the coupling effect of the freeze-thaw cycles and the $\mathrm{HCl}$ solutions, as seen below:

(1) Microstructure of sandstone in natural state and freeze-thaw cycles state

In the natural state, there are some pores in the sandstone sample but the overall density is dense. There were many mineral crystal particles with uneven size and irregular distribution, but the degree of cementation between the particles was better. At the same time, the crystal surface was rough in the natural state. However, the internal cementation of the sandstone sample after the freeze-thaw cycles was weakened and the pores were enlarged and the surface was rougher.

(2) Microstructure of sandstone under freeze-thaw cycles and $\mathrm{HCl}$ solution corrosion

The irregular mineral particles inside the sample began to diminish as the $\mathrm{pH}$ reached 5.8. The surface looked to be eroded under the impact of the $\mathrm{HCl}$ solution. Simultaneously, the pores were filled with mineral particles, and the prismatic edge of the crystal began to dissolve. When the $\mathrm{pH}$ reached 3.2, the surface fractures began to grow and join to one another. The crystal particles deposited at the pore fractures grew, and the cementation between the crystal particles diminished gradually. When the $\mathrm{pH}$ was reduced to 1.1, the pores expanded substantially and the crystal volume shrank dramatically.

\section{Conclusions}

In this paper, the dynamic compression tests of sandstone samples corroded by $\mathrm{HCl}$ solutions of varying concentrations were performed using the SHPB system under four different impact loads over the same freeze-thaw cycles. The materials' composition and microstructure were examined using an X-ray diffractometer (XRD) and scanning electron microscopy (SEM). Based on the preceding analysis, the conclusions are reached:

(1) Under the coupling effect of freeze-thaw cycles and different concentrations of $\mathrm{HCl}$ solutions, the dynamic stress-strain curves of sandstone samples experienced four stages: initial compaction stage, linear elastic deformation stage, plastic deformation stage, and failure stage. With the decrease of $\mathrm{pH}$ value, the compaction stage gradually increased and the linear elastic deformation stage gradually decreased in the prepeak region

(2) In the same dynamic load, the $\mathrm{pH}$ value has a positive linear correlation with dynamic compressive strength and dynamic elastic modulus and a negative linear correlation with dynamic peak strain. With the increase of strain rate, the sensitivity of dynamic compressive strength and dynamic peak strain to the $\mathrm{pH}$ value increased. When the strain rate ranges from $86.6 \mathrm{~s}^{-1}$ to $97.1 \mathrm{~s}^{-1}$, the sensitivity of dynamic elastic modulus to the $\mathrm{pH}$ value is the lowest. After that, the dynamic elastic modulus increases with the increase of the strain rate. In the same concentration of $\mathrm{HCl}$ solution, the dynamic compressive strength and dynamic peak strain increased linearly with the increase of strain rate. With the decrease of the $\mathrm{pH}$ value, the sensitivity of dynamic compressive strength and dynamic peak strain to strain rate increased. However, the change of elastic modulus with strain rate was not obvious

(3) The findings of X-ray diffraction revealed that when the $\mathrm{pH}$ value declined, the quantity of quartz, the primary component, increased while the concentrations of kaolinite and muscovite, the subsidiary components, decreased. The concentrations of quartz, kaolinite, and muscovite altered dramatically when the $\mathrm{pH}$ was decreased to 3.2. The corrosion of $\mathrm{HCl}$ solution affected the content of each mineral component dramatically, which modified the mechanical characteristics of sandstone 
(4) The particles in the crystal were impacted by the frost heaving force as a result of the freeze-thaw cycles, and pores and cracks formed. The internal mineral content of the sample and the $\mathrm{HCl}$ solution interacted with each other, resulting in the formation of pore fractures. The internal structure loosened, and the cementation deteriorated. Finally, the mechanical characteristics of sandstone were significantly reduced

\section{Data Availability}

Most of the data generated or analyzed during this study are included in this manuscript, and all of the data are available from the corresponding author on reasonable request.

\section{Conflicts of Interest}

The authors declare that they have no conflicts of interest.

\section{Acknowledgments}

Financial support for this work was provided by Fundamental Research Funds for the Central Universities (No. 2020ZDPYMS35).

\section{References}

[1] Q. Wang, M. He, S. Li et al., "Comparative study of model tests on automatically formed roadway and gob-side entry driving in deep coal mines," International Journal of Mining Science and Technology, vol. 31, no. 4, pp. 591-601, 2021.

[2] H. Jing, J. Wu, Q. Yin, and K. Wang, "Deformation and failure characteristics of anchorage structure of surrounding rock in deep roadway," International Journal of Mining Science and Technology, vol. 30, no. 5, pp. 593-604, 2020.

[3] T. Zhigang, Z. Chun, W. Yong, W. Jiamin, H. Manchao, and Z. Bo, "Research on stability of an open-pit mine dump with fiber optic monitoring," Geofluids, vol. 2018, 20 pages, 2018.

[4] C. Zhu, K. Zhang, H. Cai et al., "Combined application of optical fibers and CRLD bolts to monitor deformation of a pit-inpit foundation," Advances in Civil Engineering, vol. 2019, 16 pages, 2019.

[5] J. Wu, H. Jing, Q. Yin, L. Yu, B. Meng, and S. Li, "Strength prediction model considering material, ultrasonic and stress of cemented waste rock backfill for recycling gangue," Journal of Cleaner Production, vol. 276, article 123189, 2020.

[6] G. Lin, M. Li, Y. Chen et al., "Dynamic tensile mechanical properties and fracture characteristics of water-saturated sandstone under the freezing effect," International Journal of Geomechanics, vol. 21, no. 5, p. 04021044, 2021.

[7] Y. Yu, "The effect of dynamic properties of rock on blasting under high strain rate," Chinese Journal of Rock Mechanics and Engineering, vol. 12, no. 4, pp. 345-352, 1993.

[8] A. Fakhimi, P. Azhdari, and J. Kimberley, "Physical and numerical evaluation of rock strength in Split Hopkinson Pressure Bar testing," Computers and Geotechnics, vol. 102, no. June, pp. 1-11, 2018.

[9] X. Liu, F. Dai, R. Zhang, and J. Liu, "Static and dynamic uniaxial compression tests on coal rock considering the bedding directivity," Environment and Earth Science, vol. 73, no. 10, pp. 5933-5949, 2015.

[10] N. Matsuoka, "Mechanisms of rock breakdown by frost action: An experimental approach," Cold Regions Science and Technology, vol. 17, no. 3, pp. 253-270, 1990.

[11] Y. Inada and K. Yokota, "Some studies of low temperature rock strength," International Journal of Rock Mechanics and Mining Science and Geomechanics Abstracts, vol. 21, no. 3, pp. 145-153, 1984.

[12] M. Bellanger, F. Homand, and J. M. Remy, "Water behaviour in limestones as a function of pores structure: Application to frost resistance of some Lorraine limestones," Engineering Geology, vol. 36, no. 1-2, pp. 99-108, 1993.

[13] G. M. Xu and Q. S. Liu, "Analysis of mechanism of rock failure due to freeze-thaw cycling and mechanical testing study on frozen-thawed rocks," Yanshilixue Yu Gongcheng Xuebao/ Chinese Journal of Rock Mechanics and Engineering, vol. 24, no. 17, pp. 3076-3082, 2005.

[14] Y. Bai, R. Shan, Y. Ju, Y. Wu, P. Sun, and Z. Wang, "Study on the mechanical properties and damage constitutive model of frozen weakly cemented red sandstone," Cold Regions Science and Technology, vol. 171, article 102980, 2020.

[15] E. Kolay, "Modeling the effect of freezing and thawing for sedimentary rocks," Environment and Earth Science, vol. 75, no. 3, pp. 1-12, 2016.

[16] J. Li, R. B. Kaunda, and K. Zhou, "Experimental investigations on the effects of ambient freeze-thaw cycling on dynamic properties and rock pore structure deterioration of sandstone," Cold Regions Science and Technology, vol. 154, no. June, pp. 133-141, 2018.

[17] P. Wang, J. Xu, X. Fang, and P. Wang, "Energy dissipation and damage evolution analyses for the dynamic compression failure process of red-sandstone after freeze-thaw cycles," Engineering Geology, vol. 221, pp. 104-113, 2017.

[18] K. P. Zhou, B. Li, J. L. Li, H. W. Deng, and F. Bin, "Microscopic damage and dynamic mechanical properties of rock under freeze-thaw environment," Transactions of Nonferrous Metals Society of China, vol. 25, no. 4, pp. 1254-1261, 2015.

[19] Q. Ma, D. Ma, and Z. Yao, "Influence of freeze-thaw cycles on dynamic compressive strength and energy distribution of soft rock specimen," Cold Regions Science and Technology, vol. 153, no. May, pp. 10-17, 2018.

[20] J. Lu, K. Zhu, L. Tian, and L. Guo, "Dynamic compressive strength of concrete damaged by fatigue loading and freezethaw cycling," Construction and Building Materials, vol. 152, pp. 847-855, 2017.

[21] R. Liu, N. Huang, Y. Jiang, H. Jing, and L. Yu, "A numerical study of shear-induced evolutions of geometric and hydraulic properties of self-affine rough-walled rock fractures," International Journal of Rock Mechanics and Mining Sciences, vol. 127, article 104211, 2020.

[22] R. Liu, B. Li, Y. Jiang, and L. Yu, “A numerical approach for assessing effects of shear on equivalent permeability and nonlinear flow characteristics of 2-D fracture networks," Advances in Water Resources, vol. 111, pp. 289-300, 2018.

[23] J. Yu, W. Yao, K. Duan, X. Liu, and Y. Zhu, "Experimental study and discrete element method modeling of compression and permeability behaviors of weakly anisotropic sandstones," International Journal of Rock Mechanics and Mining Sciences, vol. 134, article 104437, 2020. 
[24] T. Han, J. Shi, and X. Cao, "Fracturing and damage to sandstone under coupling effects of chemical corrosion and freeze-thaw cycles," Rock Mechanics and Rock Engineering, vol. 49, no. 11, pp. 4245-4255, 2016.

[25] T. Han, X. Wang, Z. Li, D. Li, F. Xing, and N. Han, "Laboratory investigation of the mode-I fracture of sandstone caused by a combination of freeze-thaw cycles and chemical solutions," Bulletin of Engineering Geology and the Environment, vol. 79, no. 7, pp. 3689-3706, 2020.

[26] X. Yang, A. Jiang, and M. Li, "Experimental investigation of the time-dependent behavior of quartz sandstone and quartzite under the combined effects of chemical erosion and freezethaw cycles," Cold Regions Science and Technology, vol. 161, no. March, pp. 51-62, 2019.

[27] F. Gao, Q. Wang, H. Deng, J. Zhang, W. Tian, and B. Ke, "Coupled effects of chemical environments and freeze-thaw cycles on damage characteristics of red sandstone," Bulletin of Engineering Geology and the Environment, vol. 76, no. 4, pp. 1481-1490, 2017.

[28] D. Qu, D. Li, X. Li, Y. Luo, and K. Xu, "Damage evolution mechanism and constitutive model of freeze- thaw yellow sandstone in acidic environment," Cold Regions Science and Technology, vol. 155, no. July, pp. 174-183, 2018.

[29] X. Li, D. Qu, Y. Luo, R. Ma, K. Xu, and G. Wang, "Damage evolution model of sandstone under coupled chemical solution and freeze-thaw process," Cold Regions Science and Technology, vol. 162, no. February, pp. 88-95, 2019.

[30] J. Zhang, H. Deng, A. Taheri, B. Ke, C. Liu, and X. Yang, “Degradation of physical and mechanical properties of sandstone subjected to freeze-thaw cycles and chemical erosion," Cold Regions Science and Technology, vol. 155, no. July, pp. 37-46, 2018.

[31] J. Xu, H. Pu, and Z. Sha, "Mechanical behavior and decay model of the sandstone in Urumqi under coupling of freezethaw and dynamic loading," Bulletin of Engineering Geology and the Environment, vol. 80, no. 4, pp. 2963-2978, 2021.

[32] M. Yu, S. Li, Q. Sun, and S. Wang, "Influence of grain size on the strain-rate-dependent dynamic response of sandstones," Geomechanics and Geophysics for Geo-Energy and GeoResources, vol. 7, no. 3, 2021.

[33] Q. Zhu, D. Li, and W. Wang, "Mechanical behavior and permeability evolution of sandstone with confining pressure after dynamic loading," Geomechanics and Geophysics for GeoEnergy and Geo-Resources, vol. 7, no. 3, 2021.

[34] X. Liu, W. Yuan, Y. Fu, Z. Wang, L. Miao, and W. Xie, “Tests on shear strength deterioration of sandstone under the action of chemical solution and drying-wetting cycles and analysis of chemical thermodynamics," Yanshilixue Yu Gongcheng Xuebao/ Chinese Journal of Rock Mechanics and Engineering, vol. 35, no. 12, pp. 2534-2541, 2016.

[35] Y. Lin, K. Zhou, J. Li, B. Ke, and R. Gao, "Weakening laws of mechanical properties of sandstone under the effect of chemical corrosion," Rock Mechanics and Rock Engineering, vol. 53, no. 4, pp. 1857-1877, 2020. 